\title{
EL PROBLEMA DE LA LAICIDAD EN EL ORDENAMIENTO JURÍDICO
}

\author{
POR \\ Danilo Castellano $(*)$
}

\section{Actualidad de la cuestión.}

La de la laicidad, como es sabido, ha acompañado la historia de las relaciones entre el poder político y el religioso desde, por lo menos, la fundación de la Iglesia. A través de los siglos ha ido emergiendo por razones diversas y con modalidades nunca idénticas. Hoy asume particular relevancia no solamente porque está en acto una ofensiva virulenta del llamado "espíritu libre", que reivindica como derecho fundamental e irrenunciable del individuo el ejercicio de la "libertad negativa" (la libertad ejercitada con la única regla de la libertad, esto es, sin ninguna regla), sino también y sobre todo porque el ordenamiento jurídico debe vérselas siempre más con la regulación de casos que implican cuestiones éticas (pro c reación asistida médicamente, cambio de sexo, eutanasia, etc.). A veces se rechazan las normas del ordenamiento vigente porque no permiten absolutamente la libre autodeterminación: disponibilidad ilimitada del propio cuerpo y de la libertad personal, consumo libre de sustancias estupefacientes, suicidio (para el que algunos ordenamientos han establecido la asistencia de las estructuras estatales, considerándolo erróneamente un derecho subjetivo), "matrimonio" entre homosexuales, etc.

$\left(^{*}\right.$ La colección Prudentia iuris, de la editorial Marcial Pons, acaba de publicar el volumen número décimo quinto de su serie minor, del profesor Danilo Castellano, bajo el título Orden ético y derecho. Se trata de una revisión orgánica de un conjunto de textos p resentados a distintas reuniones, todas ellas de origen hispano y en su mayor parte español peninsular. Publicamos, aquí, en primicia, por su interés, el capítulo II (N. de la R.). 
No se trata hoy tanto (o no sólo) de un "choque" entre Estado e Iglesia (a veces, de hecho, viene discutido sobre todo el Estado), cuanto de dos modos inconciliables de entender la libertad y la p ropiedad, que la modernidad considera tales solamente si son ejercicio de la soberanía, entendida según la definición de Bodino.

Esto no significa que no esté también en acto un "choque" entre Estado e Iglesia, más propiamente una ofensiva contra la Iglesia, en la que se individúa "el" enemigo de la libertad luciferina, sea reivindicada bien como propia del Estado o bien del individuo. La Iglesia, en efecto, siendo depositaria de las palabras que no pasan (1), debe considerar "innegociable" el orden real, para entendernos, el querido por el Greador, el que incluso para los ateos es orden de las "cosas": que el hombre, por ejemplo, sea hombre, no depende de la fe; es una "dato" para el cre yente y para el que no cree.

\section{Novedad del problema.}

Es oportuno advertir preliminarmente que la laicidad es hoy un problema sobre todo para el laicismo. Aquélla, en efecto, no es simple reivindicación de autonomía o de independencia de las realidades temporales, como en el pasado reclamaban diversas doctrinas definidas "laicas", que a veces condujeron al "laicismo", que se manifestó esencialmente como anticlericalismo. La laicidad, actualmente, se presenta en términos nuevos, por lo que corre el riesgo de no comprender la cuestión quien la considere con las viejas categorías de laicismo/laicidad para intentar individuar los límites de la autonomía y/o de la independencia del poder político respecto del religioso. En otras palabras, considerar el problema desde esta perspectiva significa continuar razonando en términos de laicidad excluyente (la laicidad implicaría, de una

(1) Las palabras que no pasan deben entenderse como verdades duraderas e ineliminables o, mejor, como recepción (por parte de los hombres) y revelación (por parte de Dios) del orden metafísico y ético contra el que no podemos nada. Es significativo que Aristóteles haya observado que sólo el hombre tiene la palabra (Política, I, 1253a), que aunque puede manifestarse en el lenguaje y a través del lenguaje no se identifica con éste. 
parte, la exclusión del fenómeno religioso respecto del ordenamiento jurídico; y de otra pretendería regular la coexistencia sin interferencias, directas o indirectas, del poder religioso). Hoy la cuestión se plantea en términos de laicidad inclugente (la laicidad considera e incluye el fenómenos religioso, pero como derecho al ejercicio de la libertad negativa, no como deber ejercitado en la libertad (2). La "vieja" laicidad e, incluso, el "viejo" laicismo no afirmaron el "distanciamiento de las esencias"; no ponían como condición de su existencia la negación de la ve rdad. El “viejo” lai cismo (seguramente de facto, quizá también de iure) no invocaba el relativismo como presupuesto de la laicidad. $\mathrm{Ni}$ siquiera en una época caracterizada por su triunfo, como la del Risorgimento italiano, se llegó por ejemplo a legislar ignorando o violentando el o rden natural. En Italia, por ejemplo, el laicismo no introdujo ni el divo rcio ni el aborto procurado. En materia de derecho de familia y de las personas no legisló de modo racionalista, como sin embargo ocurrió en Italia después de la segunda guerra mundial, con la Constitución republicana de 1947 y con gobiernos de hombres elegidos por el electorado católico, o más recientemente en España, con el gobierno de Rodríguez Zapatero que, vigente la Constitución de 1978, ha pretendido tener el poder de cambiar, por ejemplo, la naturaleza del matrimonio.

\section{Definición de laicidad.}

Por eso, antes de nada, hay que ponerse de acuerdo sobre qué se entiende por laicidad para poder así individuar los varios aspec-

(2) Sobre la cuestión se está dando un vivo debate con incidencia significativa en los ordenamientos jurídicos y, más en general, la praxis. A título de ejemplo, puede verse entre las obras más recientes, para las posiciones diversas y, a veces, en liza, el número 24 de la revista Liberé Politique (París, diciembre de 2003), el número 445-446 de la revista Verbo (Madrid, mayo-junio-julio de 2006) y los volúmenes (además de los citados en las notas que siguen) AA.VV., Dibattito sul laicismo (a cura di Eugenio Scalfari), Roma, Gruppo editoriale L'Espresso, 2005; G. Giorello, Di nessuna chiesa, Milano, Cortina editore, 2005; AA.VV., Chiesa e Stato nell'Eu ropa contemporanea (a cura di Danilo Castellano), Napoli, Edizioni Scientifiche Italiane, 2006; AA.VV., Lessico della laicità (a cura di Giuseppe Dalla Torre), Roma, Studium, 2007; A. SCOLA, Una nuova laicità, Venezia, Marsilio, 2007; G. Zagrebelsky, Lo Stato e la Chiesa, Roma, Gruppo editoriale L'Espresso, 2007. 
tos problemáticos de las cuestiones que plantea al ordenamiento jurídico.

Hay que observar primeramente que la laicidad rechaza sobre todo -como declaran sus propios sostenedores (3) - la verdad, p roclamando el propio "distanciamiento de las esencias". De ahí se sigue que las esencias (la naturaleza humana, la naturaleza del matrimonio, etc.) no pueden ser reguladoras de las normas del ordenamiento, sino que éstas son (o pretenden serlo) los criterios constitutivos de los distintos institutos jurídicos y de los derechos. En último término, el ordenamiento jurídico se convierte en condición del derecho. La laicidad reclama, por consiguiente, la llamada "libertad de conciencia", la libertad de creencia, la libertad de conocimiento, reduciendo respectivamente la conciencia a facultad del vitalismo (naturalismo), la creencia a dogmatismo de la opinión subjetiva y el conocimiento a puro conocimiento del método, erigido erróneamente como objeto del conocimiento mismo. Así, por ejemplo, el derecho consistiría en la metodología de la jurisprudencia de las definiciones (impropiamente llamada de los conceptos), en lugar de en la individuación de la equidad y, por tanto, en la jurisprudencia de los casos. Estaríamos en presencia del nihilismo jurídico (4), en cuanto que el derecho producido por el ordenamiento (en lugar de ser su condición) dependería del poder soberano, es decir, de la voluntad acompañada del poder de hacerla efectiva, sea la del Estado, sea la del pueblo. En otras palabras, en uno y otro caso, el manantial (o sea, la fuente de producción) del derecho y de la ley, que regulan la vida en común, sería la voluntad o, más propiamente, la voluntad/poder: el Estado o el pueblo tendrían el poder (a veces definido "constituyente", en cualquier caso siempre "ordenador"). Por esto, laici dad y democracia moderna se hallan estrechamente ligadas; son dos caras de la misma moneda. Como ha escrito un autor francés,

(3) Cfr., per esempio, G. BonIOLO, "Introduzione" a AA.VV., Laicità. Una geo grafia delle nostre radici, Torino, Einaudi, 2006, p. XIV.

(4) Al nihilismo jurídico lleva necesariamente el positivismo jurídico (absoluto y "puro"), que paulatinamente se ve "obligado" a identificar el derecho con el método, con la forma, con la técnica, etc. Véase sobre el tema, en sentido acorde a la tesis, N. IRTI, Nichilismo giuridico, Roma-Bari, Laterza, 2005. 
defensor brioso del "laicismo", democracia y la laicidad remiten a la misma idea: la de una soberanía ejercitada por el pueblo sobre sí mismo (5). Sin embargo hay que estar atentos, porque la soberanía sería "limitada" (o sea, se contradiría a sí misma) si pretendiese legitimar su ejercicio por el consensa la mayoría, este caso, ejercitaría su poder sobre la minoría y, en todo caso, sobre quienes por distintas razones no tuvieron la posibilidad de concurrir a su formación, adhiriéndose (menores, ciudadanos privados de de rechos políticos, etc.).

De hecho, por tanto, a veces una clase, por usar el lenguaje marxista, o un grupo, ejercitaría la soberanía en nombre del pueblo. Una parte de él sería, en estos casos, súbdito en vez de soberano. La laicidad, según la opinión concorde de quienes la sostienen, es esencialmente emancipación, emancipación de cada uno y, por tanto, de todos; en cuanto tal ésta rechaza toda forma de paternidad (considerada paternalismo), de moral (considerada límite o "borde" de la libertad), de observación del sentido de las "cosas" [considerada asignación arbitraria de sentido a las mismas (finalismo) y, por lo mismo, imposición del hombre sobre el hombre], de toda forma de autoridad (consideradas instrumento para "escayola r" el espíritu). La laicidad, así, es emancipación, como realización integral de la liberad negativa, es decir, de la libertad propugnada por el racionalismo; y se convierte en laicismo cuando, aunque sea bajo diversas formas, asume una posición militante.

\section{La vía "francesa” y la vía "americana”.}

Son dos las formas principales asumidas por la laicidad y que tienen particular relieve también para el ordenamiento jurídico. Hay, en efecto, una vía "francesa", que algunos llaman también e u ropeo-continental, y una vía "americana". La vía "francesa" privilegia los derechos de la identidad colectiva, también llamada cuerpo político, Estado o República. La ratio que la caracteriza lleva en último término no sólo a la subordinación del individuo

(5) Cfr. H. Pena-Ruiz, Qu’est-ce que la laïcité?, París, Gallimard, 2003, pág. 27. 
al Estado, sino también a la pretensión de que aquél piense y quiera prog resivamente como piensa y quiere el Estado. Aunque p roclame reiteradamente el derecho a la libertad de conciencia, éste se halla subordinado a la salvaguarda del orden público, que no es necesariamente el orden en sí; más aún, con frecuencia, no lo es en absoluto. Para la laicidad, que se distancia de las esencias, no lo es nunca. En otras palabras, la República se hace garante de la tutela de la libertad de conciencia a condición de que ésta se ejercite dentro de los límites y, por tanto, de conformidad con las rationes del ordenamiento jurídico, sacralizado como religión civil. El individuo es libre en la libertad del Estado y en virtud del Estado. Sus derechos, puestos convencionalmente (la ley, de hecho, se define como expresión de la voluntad general y se considera fuente del derecho), son los "derechos civiles", derechos precarios y de contenido variable aunque se definan como naturales e imprescriptibles. Esto ocurre no solamente en presencia de la "ideología de Mariana", es decir, en presencia de la soberanía del Estado ejercitada de manera "fuerte"; ocurre también en presencia de la soberanía popular respecto de la que el Estado es considerado servidor (como expresamente estatuye, por ejemplo, la Constitución española de 1978, en su artículo 1.2), o sea, in presencia de la soberanía ejercitada de manera "débil". Bastará un ejemplo para apuntar "concretamente" el problema. LaRepública italiana ha legalizado la objeción de conciencia del personal médico y sanitario a la práctica del aborto procurado (Ley 194/1978). Ha reconocido un derecho indiscriminado a la objeción para la que basta la declaración del interesado. En una primera lectura parecería que se reconoce el derecho "laico" a la libertad de conciencia de modo absoluto. Sin embargo, no es así. El Estado italiano, en efecto, reconoce este derecho al médico y al personal sanitario que se declara objetor, con la condición de que en circunstancias particulares (cuando se entiende que hay peligro de vida para la gestante) el aborto pueda ser practicado en todo caso. Si en esta circunstancia no pudiese practicarse el aborto la objeción del personal médico y sanitario es tamquam non esset. Lo que significa que la soberanía (del Estado o del pueblo) no reconoce lo que la laicidad considera el más fundamental de los derechos 
fundamentales. Lo que levanta, a continuación, una cuestión todavía más radical y más general sobre la que volve remos dentro de poco: ¿es posible una absoluta "neutralidad" del ordenamiento jurídico?

Volviendo, sin embargo, a la laicidad según el (viejo) modelo francés, no hay duda de que ésta, reclamando el derecho a la liber tad negativa por parte de la identidad colectiva o del Estado, re ivindica antes que nada el derecho/poder de "ordenar" la sociedad según un orden convencional cualquiera (el poder constituyente, de hecho, se considera omnipotente); este orden, construido sobre planos, es siempre y sólo el orden de la legalidad, esto es, el o rden público efectivo al que se subordina cualquier otro orden. Resulta significativo, por ejemplo, que el llamado derecho privado o civil esté subordinado al ordenamiento constitucional e incluso, en ausencia de la Constitución (entendida como ley fundamental), como ocurría en los regímenes del absolutismo, al de recho público.

Esta laicidad cae en diversas contradicciones, que algunos autores (por ejemplo, Rousseau), han considerado (erróneamente) poder superar recurriendo en último término al poder $y$, por tanto, sacrificando totalmente el "espíritu libre", esto es, el que rechaza toda forma de limitación; lo que ha conducido al "bloqueo" del proceso de emancipación perseguido por la laicidad y a la génesis del totalitarismo que, según la definición de Volkoff (6), consiste propiamente -ya lo hemos señalado- en la pretensión de que el individuo/ciudadano piense y quiera como piensa y quiere el Estado.

Es esta una de las razones por las que la laicidad entendida según el modelo francés, ha entrado en crisis: la heterogénesis de los fines a que ha llevado, ha hecho evidente incluso a quienes todavía la sostenían que hay cuestiones ineludibles que se presentan como aporías de los ordenamientos jurídicos "laicos" contemporáneos. Apuntemos sólo dos: a) Para ser "laicos" -se dice- es necesario rechazar la pertenencia a cualquier "Iglesia/Estado", o

(6) Cfr. V. Volkoff, Il Re, Napoli, Guida, 1989, pág. 41. Puede verse también, sobre el asunto, D. CASTEllano, La verità della politica, Napoli, Edizioni Scientifiche Italiane, 2002, págs. 165-175. 
sea, es necesario creer (y, por tanto, pertenecer) a cualquier "religión", incluida "la religión civil". Lo que evidentemente representa un problema para la legalidad o, mejor, para su legitimación. b) Para afirmar la laicidad, en consecuencia, el Estado no debería imponer nada: ni un ordenamiento propio, esto es, un conjunto coherente de normas que tienen la finalidad de instaurar un orden; ni las convicciones y las creencias de la mayoría (ni siquiera, por tanto, la religión de la mayoría); ni una visión del hombre (y tampoco una visión "laica" del hombre, según la que su esencia sería solamente su libertad); ni una (o, mejor, la) concepción del bien (el bien resultaría enemigo de la libertad) (7). El Estado, para ser auténticamente laico, debería profesar la indiferencia, que no debe entenderse como "desinterés", sino más bien como "equidistancia" de toda opición y todo proyecto, porque sólo de este modo se garantizarían la libertad (negativa) y la igualdad (ilustrada), consideradas "principios" irrenunciables de los ordenamientos constitucionales occidentales contemporáneos.

Parte de la cultura político-jurídica contemporánea, intentando superar las dificultades creadas por la laicidad, entendida según el modelo francés, ha recurrido a la laicidad entendida según el modelo americano. El individuo y no el Estado es quien tendría el derecho de ejercitar la libertad negativa. El Estado (o, mejor, lo que se sigue llamando Estado) sería la institución al servicio de los p royectos de la sociedad civil o, en una versión más radical y coherente, de los proyectos individuales. La persona -se afirma- tendría el derecho a la absoluta autodeterminación y el ordenamiento jurídico sería instrumental (y, por lo mismo, subordinado) a su voluntad, a cualquiera que sea su voluntad. Sin embargo, como quiera que la convivencia (aunque sea entendida en modo reductivo como un estar a lado de los otros) no puede eliminarse, debe garantizarse en todo caso un orden público, condicio sine qua non

(7) Las teorías políticas liberales, incluidas las comunitaristas, sostienen que la idea pública del bien es (y debe permanecer) ajena al ordenamiento jurídico, puesto que la sociedad liberal debe permanecer neutral respecto de la vida buena (cfr., por ejemplo, Ch. TAYLOR, The Politics of Recognition, Princeton, Princeton University Press, 1992, ahora en traducción italiana, J. HABERMAS-Ch. TAYLOR, Multiculturalismo, Milano, Feltrinelli, 1998, págs. 44-45). 
de la misma convivencia. Esto implica la imposibilidad de acoger íntegramente el derecho a la libertad de conciencia y, consiguientemente, que la emancipación "laica" no pueda tener plena realización. También la laicidad, en efecto, entendida según el modelo americano, encuentra límites y cae en contradicicciones. Primeramente se ve obligada a formular la teoría del republicanis mo global, esto es, a resaltar la ineliminibilidad de un orden, aunque sea racionalista, necesario para toda convivencia. Lo que excluye que se pueda reconocer el derecho al ejercicio absolutamente libre de la soberanía de la voluntad individual. Comporta, después, la exigencia de individuar el criterio y el fundamento de la legitimidad del orden republicano. Comporta, además, de una parte la negación de que la mayoría, en cuanto mayoría, tengo de recho a "privilegios" (que terminarían por anular la libertad y la igualdad laicas) y, de otra, que el orden público (cualquier orden público) venga garantizado en todo caso. Para intentar resolver estos (y otros) problemas, la laicidad según el modelo americano ha creído encontrar la solución en el orden público "modular" (o en el orden de la $r e d$ ): pero se trata de orden precario y variable, que se compone y descompone continuamente según prevalezca una u otra mayoría contingente (jcon lo que se rodea sin resolverlo el problema de la laicidad). La inestabilidad resulta lo único estable: la institución pública garantiza que no prevalezca ningún orden y, por lo mismo, es garantía de la estabilidad del relativismo.

\section{Apuntes sobre el "caso italiano" y sus contradicciones.}

Es oportuno, llegados a este punto, referirse al caso italiano, po rque es particularmente significativo para comprender la evolución (fatigosa e incierta) del modelo francés al modelo americano de laicidad.

No sólo eso. El caso italiano revela también las contradicciones insuperables en las que incurre el ordenamiento jurídico que asuma la laicidad, entendida como antes hemos hecho, como su presupuesto. No hay duda de que el ordenamiento jurídico italia- 
no, y en particular el constitucional, es hoy "laico". Lo reconoce la doctrina hegemónica, casi la generalidad de la doctrina; lo ha sentenciado reiteradamente la Corte constitucional; han tomado nota el Gobierno italiano, presidido a la sazón por Craxi, y la Santa Sede, con la ocasión de la revisión de los Pactos lateranenses en 1984. En el plano jurídico-positivo la laicidad ha sido introducida formalmente con la constitución de 1947. El ordenamiento precedente, el risorgimentale, se había re velado de hecho "laico" y fuertemente anticlerical. El Estatuto albertino, sin embargo, no legitimaba ni la laicidad ni el anticlericalismo: su artículo 1 (el único escrito personalmente por el rey Carlos Alberto) era claro y lapidario en este sentido, aunque no faltaran las interpretaciones de que constituiría un "cuerpo extraño" respecto al articulado sucesivo (lo que habría podido sostener la teoría del "laicismo implícito" del Estatuto albertino).

Con la Constitución republicana, por tanto, se acogieron las instancias de la laicidad. En primer lugar afirmando que el punto de Arquímedes del ordenamiento constitucional es la soberanía, que -como hemos recordado- es el principio irrenunciable de la laicidad, acogiendo, después, la concepción ilustrada, esto es, laica, de la libertad y de la igualdad; codificando, además, los derechos humanos como se han afirmado en la experiencia histórica a la luz de las Declaraciones y de las Constituciones modernas.

La laicidad del ordenamiento italiano se impuso primero según el modelo francés, para evolucionar luego coherentemente según el modelo americano. Es significativo en este sentido lo ocurrido con el juramento, a propósito del cual la evolución de la legislación y de la jurisprudencia (sobre todo la de la Corte constitucional), demuestra la lenta transición de la laicidad del modelo francés al americano. La institución del juramento había sido ya objeto de polémica por parte de los liberales en el siglo XIX. Entonces se resolvió la cuestión con el "compromiso Vigliani" (Ley 3184/1876). Alfredo Rocco, en los años treinta del siglo apenas terminado, la volvió a proponer en términos no laicos, sino incluso casi religiosos (la "cosa" puede sorprender, porque el fascismo, no obstante la firma de los Pactos lateranenses en 1929, 
fue un régimen "laico"). Con la entrada en vigor de la Constitución republicana el 1 de enero de 1948 el juramento volvió a ser discutido. La Corte constitucional, al inicio, resolvió a favor de la "discriminación por ley" y, por ello, que las normas reguladoras del juramento, además de no ser inconstitucionales, no violaban los derechos de la persona, toda vez que estaban previstas en el ordenamiento.

Compartió esta tesis, aunque con argumentaciones parcialmente diversas, una doctrina autorizada (Esposito, Allorio, Bigiavi, etc.), que no advirtió la exigencia de poner en discusión los dogmas de lalaicidad político-jurídica de inspiración francesa. Más adelante, la Corte cambió de parecer en su sentencia 117/1979. Afirma tímidamente que el juramento -contrariamente a su naturaleza, ya expuesta por Cicerón (8) - concierne sólo a la "conciencia" y no a la relación con Dios. Por eso puede haber un juramento sobre sólo el honor. El cambio respecto de la jurisprudencia anterior es neto y evidencia la opción inmanentista y laica, que vendrá confirmada más recientemente en su sentencia $334 / 1996$, con la que la Corte constitucional, citando sus anteriores 203/1989 y 13/1991, afirma explícitamente la laicidad del Estado, que lleva consigo, entre otras cosas, la garantía constitucional de la libertad de conciencia como aspecto de la dignidad de la persona humana, reconocida y declarada inviolable en el artículo 2 de la Constitución, y la distinción (en realidad separación) del orden civil del moral y religioso (9). Esto no significa que el Estado y su ordenamiento jurídico laico sean contrarios a la religión o, mejor, estén "cerrados" frente a las instancias religiosas individuales. Significa, más bien, que en sí y para sí son indifere ntes frente a otras experiencias o exigencias "personales". Las tutelan todas indiscriminadamente. Garantizan el derecho individual a la religión, al mismo tiempo que el derecho individual al ateísmo activo. Así, por ejemplo, puede subsistir el delito de vilipen-

(8) Cfr. M.T. Cicerón, De officis, 3, 29, 104: "Est enim -escribe Cicerón- iurandum adfirmatio religiosa, quod autem adfirmata quasi Deo teste promiseris, id tenendum est”.

(9) Sobre estas cuestiones resulta útil la lectura del libro de P. G. GRASSO, Costituzione e secolarizzazione, Padova, Cedam, 2002. 
dio de la religión, siempre que se considere solamente ofensa al sentimiento religioso de la persona. So b re lo que no hay duda es sobre la inconstitucionalidad en sí mismo del delito de vilipendio de la religión, que un ordenamiento "laico" como el italiano no puede reconocer.

\section{La imposible "neutralidad" del ordenamiento jurídico o la intrínseca contradicción de la indiferencia.}

Ya hemos anotado que, en el campo jurídico-político, la laici dad no logra actualizar plenamente su opción inmanentista-individualista. Esto ha llevado a "casos" que han suscitado debates y alimentado polémicas en el mundo occidental. Cuando, en efecto, la laicidad se ha conve rtido en laicismo, esto es, laicidad militante, ha conducido a la arbitraria (aunque se efectúe por ley) privación de bienes de propiedad privada individual y colectiva. Bastaría pensar, por ejemplo, en las leyes Siccardi (que abolieron en 1848 el fuero eclesiástico y el derecho de asilo) del Reino de Cerdeña, que prepararon el terreno a las leyes Ratazzi (que en 1855 suprimieron las órdenes religiosas y confiscaron sus bienes) o la ley francesa de 1905 de separación del Estado y las Iglesias (nótese "iglesias", ¡en plural!). En tiempos más cercanos a nosotros, como es sabido, la laicidad ha portado a la prohibición de la oración, la lectura de la Biblia y las rep resentaciones sagradas en las escuelas públicas o, en el Reino de Gran Bretaña, hasta al consumo en las meriendas de las brioches tradicionales con forma de c ruz. En Francia se ha regulado (y restringido) por ley el uso en público de símbolos religiosos y se ha llegado a impedir al capellán de un liceo de Toulon que llevase en público la sotana. En Alemania, el Tribunal administrativo de Baden-Württemberg ha p rohibido a las monjas llevar velo dentro de los edificios escolares. En los Estados Unidos, por su parte, causó sensación en 2003 la suspensión de un juez, Ray Moore, culpable de haber puesto delante de la sede de un tribunal de Alabama, en Mbntgomery, una lápida con los Diez Mandamientos, quitada por orden del Tribunal Sup remo Federal. Son todos hechos que demuestran que 
la laicidad, para afirmarse, debe negar validez a los principios que p roclama y que considera de por sí esenciales. ¿Es esta una contradicción meramente práctica de la laicidad o es el signo de una aporía inevitable? En otras palabras, ¿podría ser de otro modo? La respuesta es negativa, porque no puede darse un ordenamiento jurídico indiferente. Dicho de otra manera, el ordenamiento jurídico necesita de una visión "positiva" del orden, más aún necesita de la individuación del orden en sí, esto es, debe pronunciarse necesariamente sobre lo justo y lo injusto, sobre el bien y el mal, sobrelo equitativo y lo inicuo, porque debe prescribir y prohibir. La cuestión ha sido levantada recientemente por el constitucionalista estadounidense Weiler cuando se ha preguntado si y sobre qué base es posible prohibir el sacrificio de seres humanos por razones (consideradas de buena fe) religiosas, sobre todo si el sacrificado fuese capaz de obrar y consintiese. La pregunta tiene tanto más sentido desde el momento en que hay ordenamientos, como el de los Países Bajos, por ejemplo, que reconocen como de recho subjetivo el suicidio asistido, forma radical de autodeterminación o de libertad de conciencia, al lado del que la decisión de sacrificarse por razones (consideradas) religiosas resultaría, al menos fenomenológicamente, más noble.

El ordenamiento jurídico "laico", por otra parte, no está en condiciones de ejercitar siquiera la función "mínima” requerida por una convivencia ordenada. Resulta imposible, en efecto, resolver incluso las cuestiones de la vida cotidiana rechazando el conocimiento de la verdad o practicando el llamado "distanciamiento de las esencias". ¿Sobre qué presupuestos podrá responderse, por ejemplo, a la pregunta acerca de la legitimidad o no del maltrato de los animales o sobre la licitud del sacrificio ritual judío o mahometano que, para algunos, es causa de turbación a causa de su (considerada) crueldad? No es suficiente, desde luego, la invocación de la ofensa del sentimiento individual o de grupo. No sólo porque, por una parte, todo sentimiento, desde este ángulo, debería ser reconocido digno de tutela (y, en consecuencia, no podría individuarse ningún criterio de discriminación), sino también y sobre todo, por otra, porque es evidente que no todos los sentimientos merecen tutela y, consiguientemente, pue- 
den ser legitimados, tutelados y garantizados. $\mathrm{O}$, incluso, ¿̨por qué debe considerarse absolutamente contraria a derecho la esclavitud? En el fondo Kelsen aplicaba coherentemente los principios de la laicidad cuando sostenía que si un individuo capaz de obrar se da libremente en esclavitud ejercita un acto de libertad. Todavía, a la luz de los principios de la laicidad, debería estar consentido disponer absolutamente de uno mismo; y por tanto habrían de considerarse contrarias a un ordenamiento jurídico laico las normas que no permiten disponer del propio cuerpo (mutilación no terapéutica, su cesión retribuida para la experimentación farmacológica y clínica, el cambio de sexo, la eutanasia, etc.). Difícilmente, pues, la libertad de conciencia laica podría consentir con el ejercicio de la patria potestad, puesto que la educación tanto como las curas sanitarias (sobre todo las preventivas, como vacunaciones) del menor o de quien no tiene capacidad de obrar deberían considerarse contrarias a la libre autodeterminación.

No son sino ejemplos que, nos parece, evidencian la contradicción radical entre ordenamiento jurídico y laicidad y, más generalmente, entre derecho y libertad negativa, que es un problema heredado de la cultura protestante y acentuado por su secularización.

\section{Conclusión.}

La laicidad por tanto, acaba en un callejón sin salida. No resuelve ningún problema político o social; más aún, los agrava . La laicidad incluyente, después, que a algunos ha parecido y parece como la vía para la superación definitiva de la laicidadexcluyen te, se revela todavía más absurda que ésta puesto que no puede siquiera buscar legítimamente la (falsa) solución "ideológica” de la laicidad exluyente que, aunque absurdamente, conservaba un aspecto "positivo" frente al nihilismo político y jurídico al que conducen el subjetivismo y el relativismo. La laicidad incluyente incurre en diversas contradicciones radicales. Bastaré ejemplificar observando: 1) que no puede admitir ningún ordenamiento o, mejor, que puede admitir solamente los ordenamientos que, al 
gozar del consenso de aquellos a los que dirige sus mandatos, son o rdenamientos inútiles, porque inútil es el conjunto coherente de normas que ordena y prohíbe lo que los destinatarios del mandato harían o dejarían de hacer por decisión autónoma; 2) que está destinada a la parálisis, puesto que un ordenamiento que aspire a tutelar el ejercicio de la libertad negativa rep resenta la negación de sí mismo; 3) que la tutela de opciones contradictorias constituye la premisa de conflictos incurables. La laicidad, por tanto, tal y como actualmente se presenta, no puede dar respuesta a los problemas que la convivencia presenta. Ella, por lo mismo, es "el" p roblema que el laicismo encuentra y no resuelve, incluso que no puede resolver si antes no niega las premisas desde la que actúa.

La laicidad, sobre todo la incluyente, por lo tanto, en última instancia es incompatible con todo ordenamiento jurídico. 